\title{
PROFIL PENALARAN ANALOGI SISWA DALAM PEMECAHAN MASALAH MATEMATIKA DITINJAU DARI KEMAMPUAN MATEMATIKA
}

\author{
Tri Wilfi Iqlima \\ Pendidikan Matematika, FMIPA, Universitas Negeri Surabaya, e-mail: triiqlima@mhs.unesa.ac.id \\ Susanah \\ Pendidikan Matematika, FMIPA, Universitas Negeri Surabaya,e-mail: susanah@unesa.ac.id
}

\begin{abstract}
Abstrak
Penalaran analogi adalah proses berpikir logis dan analitis dalam pengambilan kesimpulan berdasarkan persamaan antara dua hal yang dibandingkan. Tujuan dari penelitian ini untuk mendeskripsikan penalaran analogi siswa dalam pemecahan masalah matematika ditinjau dari kemampuan matematika tinggi, sedang, dan rendah. Penelitian ini merupakan penelitian deskriptif dengan pendekatan kualitatif. Subjek dalam penelitian ini terdiri dari 1 subjek dengan kemampuan matematika tinggi, 1 subjek dengan kemampuan matematika sedang, dan 1 subjek dengan kemampuan matematika rendah yang dipilih dari 33 siswa kelas IX-H SMP Negeri 5 Surabaya. Hasil analisis Tes Pemecahan Masalah dan wawancara menunjukkan bahwa siswa berkemampuan matematika tinggi, sedang, dan rendah melakukan proses encoding dibuktikan dengan menyebut dan menjelaskan informasi antara soal sumber dan soal target dengan alasan yang logis. Setiap subjek juga menyebutkan dan menjelaskan konsep yang digunakan untuk menyelesaikan soal sumber yang artinya setiap subjek telah melakukan proses inferring. Bedanya, subjek dengan kemampuan matematika tinggi melakukan dua prose pelanaran lainnya yaitu mapping dan applying. Subjek dengan kemampuan matematika sedang hanya melakukan satu dari dua indikator pada proses mapping maka proses penalaran analogi yang dilakukan subjek tersebut yaitu encoding dan inferring. Sedangkan siswa dengan kemampuan matematika rendah terhenti pada proses encoding dan inferring.
\end{abstract}

Kata kunci: Penalaran Analogi, Kemampuan Matematika

\begin{abstract}
Analogy reasoning is the process of thinking logically and analytically in making conclusions based on the similarities between the two things being compared. The purpose of this study is to describe the analogy reasoning of students in solving mathematical problems in terms of high, medium, and low mathematical abilities. This research is a descriptive study with a qualitative approach. The subjects in this study consisted of 1 subject with high mathematical ability, 1 subject with medium mathematical ability, and 1 subject with low mathematical ability selected from 33 students of IX-H grade at SMP Negeri 5 Surabaya. The results of the analysis of Problem Solving Tests and interviews show that students with high, medium, and low mathematical abilities carry out the encoding process as evidenced by mentioning and explaining information between the source and target questions with logical reasons. Each subject also mentions and explains the concepts used to solve source problems, which means each subject has an inferring process. The difference is, subjects with high mathematical abilities do two other processes, namely mapping and applying. Subjects with medium mathematical abilities are only doing one of the two indicators in the mapping process, so the analogy reasoning process carried out by the subject is encoding and inferring. While students with low mathematical abilities are stopped in the encoding and inferring.
\end{abstract}

Keywords: Analogy Reasoning, Mathematical Abilitiy

\section{PENDAHULUAN}

Penalaran merupakan hal yang penting dalam pembelajaran matematika khususnya dalam pemahaman konsep dan pemecahan masalah. Hal tersebut dibuktikan dengan dimensi pedagogik modern yang ditekankan dalam pembelajaran yaitu pendekatan scientific (ilmiah) yang salah satunya adalah menalar (Kemendikbud, 2013). Selain itu dalam konferensi guru matematika internasional,

\begin{abstract}
National Council of Teacher of Mathematics juga menyatakan bahwa terdapat prinsip dan standar matematika di sekolah agar pembelajaran menjadi bermakna yang salah satunya adalah reasoning and proof atau penalaran dan pembuktian (NCTM,2000). Salah satu jenis penalaran dalam matematika adalah penalaran analogi. Penalaran analogi menurut Vybihal merupakan proses mendapatkan dan mengadaptasi pengetahuan atau
\end{abstract}


penyelesaian lama untuk menyelesaikan masalah baru (Vybihal, 1989). Genter menyatakan bahwa penalaran analogi adalah jenis penalaran yang berlaku antara contoh atau kasus spesifik, dimana apa yang diketahui tentang satu contoh digunakan untuk menyimpulkan informasi baru tentang contoh lainnya (Genter, 2013). Contoh yang dimaksud sebelumnya merupakan situasi yang belum diketahui atau belum dikenal sebelumnya namun memiliki korelasi satu sama lain. Pendapat lain disampaikan oleh English yang menyatakan bahwa dalam penalaran analogi kesimpulan yang didapat dari masalah yang telah diketahui digunakan untuk menyelesaikan masalah baru. Penalaran analogi digunakan sebagai model untuk memahami dan menarik kesimpulan baru pada situasi atau target yang belum diketahui (English, 2004). Dalam penalaran analogi terdapat situasi yang disebut analog sumber atau masalah sumber yang artinya adalah masalah dasar untuk menyelesaikan masalah lain yang analog dan masalah target yang artinya adalah masalah yang penyelesaiannya merupakan adaptasi dari masalah sumber.

Penalaran analogi dibedakan menjadi tiga macam, yaitu (1) Reasoning with classical analogies,(2) Reasoning with problem analogies, dan (3) Reasoning with pedagogical analogies (English, 1999). Pada penelitian ini yang akan dibahas adalah reasoning with problem analogies karena penalaran analogi yang mencakup pemecahan masalah adalah penalaran analogi jenis ini. English menyatakan bahwa terdapat proses penalaran analogi dalam pemecahan masalah yaitu encoding, inferring, mapping, dan applying English (2004). Encoding (Pengkodean) merupakan proses mengidentifikasi informasi yang terkandung dalam masalah sumber dan masalah target meliputi mengidentifikasi informasi yang diketahui, informasi yang ditanyakan, ciri-ciri soal, struktur soal, hubungan antara informasi pada masalah sumber dan masalah target, atau informasi tambahan yang dapat digunakan untuk menyelesaikan masalah sumber dan masalah target. Inferring (Penyimpulan) merupakan proses menentukan penyelesaian masalah sumber. Untuk menyelesaikan masalah sumber diperlukan ide-ide atau objek matematika berupa fakta, konsep, operasi atau prinsip yang saling berhubungan. Ide-ide atau objek matematika yang saling berhubungan tersebut kemudian dirangkai menjadi struktur penyelesaian masalah sumber. Mapping (Pemetaan) merupakan proses pemetaan struktur penyelesaian masalah sumber ke masalah target. Rangkaian ide-ide matematika berupa struktur masalah sumber dikaitkan dengan masalah target untuk mencari ideide matematika yang bersesuaian dengan masalah target. Ide-ide matematika yang bersesuaian tersebut kemudian dirangkai menjadi struktur penyelesaian masalah target. Applying (Penerapan) merupakan proses pengaplikasian struktur penyelesaian masalah sumber ke masalah target dengan disertai alasan yang logis.

Dalam pemecahan masalah penalaran analogi melibatkan masalah sumber dan masalah target. Masalah sumber adalah masalah matematika yang pernah diselesaikan oleh siswa. Masalah sumber diberikan sebelum masalah target, berupa masalah yang mudah dan sedang, dan dapat membantu menyelesaikan masalah target atau sebagai pengetahuan awal dalam masalah target. Sedangkan yang dimaksud masalah target adalah masalah matematika yang diberikan setelah siswa menyelesaikan masalah sumber. Masalah target berupa masalah sumber yang dimodifikasi atau diperluas yang strukturnya berhubungan dengan struktur masalah sumber, dan berupa masalah yang kompleks. Menurut English, selama siswa membuat hubungan analogi, siswa membutuhkan pengertian secara jelas struktur dari masalah sumber dan harus dapat mengerti hubungan korespondensi diantara masalah sumber dan masalah target. Ketika siswa gagal dalam mengerjakannya, maka belajar siswa tersebut tidak bermakna (English, 1999).

Seorang siswa dikatakan melakukan penalaran analogi dalam memecahkan atau menyelesaikan masalah matematika jika perserta didik tersebut melakukan beberapa aktivitas seperti mengidentifikasi apakah ada hubungan dan kesesuaian informasi antara masalah yang dihadapi (target) dengan pengetahuan yang telah dimiliki (sumber), mengetahui bagaimana cara menggunakan masalah sumber dalam memecahkan masalah target (Novick dan Holyoak, 1991). Penalaran analogi dalam pemecahan masalah, siswa diberikan soal sumber dan soal target dan siswa tersebut harus menganalisis struktur penyelesaian antara keduanya. Setelah menemukan informasi pada soal sumber, siswa akan menemukan struktur penyelesaian soal sumber. Struktur penyelesaian tersebut kemudian dihubungkan dengan informasi pada soal target dan diadaptasi untuk menyelesaikan soal target. Siswa tetap dikatakan melakukan proses penalaran analogi dalam pemecahan masalah meskipun soal target tidak terselesaikan atau keempat proses penalaran analogi tidak semuanya dilakukan. Karena proses penalaran analogi tidak memerhatikan urutan dan menuntut semua proses terpenuhi. Dapat dikatakan ada faktor lain yang memengaruhinya. Salah satu faktor tersebut adalah kemampuan matematika siswa. Kemampuan matematika memiliki kaitan dengan potensi seseorang yang meliputi pengetahuan dan keterampilan dalam berpikir, bernalar, memecahkan masalah, dan sebagainya (Sa'dullah, 2003). Sehingga dapat diketahui bahwa kemampuan matematika yang dimiliki seseorang akan mempengaruhi proses bernalar siswa tersebut. 


\section{METODE}

Penelitian ini merupakan penelitian deskriptif dengan pendekatan kualitatif. Instrumen dalam penelitian ini meliputi instrumen Tes Kemampuan Matematika (TKM), Tes Pemecahan Masalah (TPM) yang terdiri dari soal sumber dan soal target, dan pedoman wawancara. Setelah instrumen tersebut dikonsultasikan ke dosen pembimbing dan guru mitra, selanjutnya instrumen divalidasi oleh validator. Instrumen dinyatakan valid jika mendapatkan minimal rata-rata nilai 4 dari 5 skala penliaian dan mendapatkan setidaknya kriteria C (dapat digunakan dengan banyak revisi) dari 4 kriteria penilaian secara umum. Tes kemampuan matematika diberikan pada siswa untuk menentukan subjek penelitian. Peneliti mengelompokkan siswa menjadi kelompok siswa dengan tingkat kemampuan matematika tinggi, sedang, dan rendah. Dari kelompok tersebut dipilih masing-masing satu subjek pada setiap kategori. Selanjutnya peneliti memberikan tes pemecahan masalah kepada subjek yang telah dipilih. Tes Pemecahan Masalah diberikan untuk mengetahui proses penalaran analogi masing-masing subjek. Setelah tes pemecahan masalah dilaksanakan, peneliti melakukan wawancara terhadap subjek untuk mengetahui proses penalaran analogi yang belum terungkap di lembar tes pemecahan masalah subjek.

\section{HASIL DAN PEMBAHASAN}

Berdasarkan data yang diperoleh diketahui bahwa siswa dengan kemampuan matematika tinggi melakukan pengerjaan yang mengindikasikan semua indikator proses penalaran analogi yaitu encoding, inferring, mapping, dan applying. Siswa dengan kemampuan matematika tinggi menjelaskan informasi yang diketahui pada soal sumber maupun soal target dengan alasan yang logis juga mengaitkan hubungan antara informasi pada soal sumber dan menjadikan hal tersebut acuan untuk menyelesaikan soal target. Siswa dengan kemampuan matematika tinggi menyelesaikan soal sumber dan soal target dengan menyebutkan dan menjelaskan konsep yang digunakan serta hubungan antara konsep matematika pada penyelesaian soal sumber dan soal target disertai alasan yang logis. Proses penalaran analogi siswa dengan kemampuan matematika tinggi meliputi encoding, inferring, encoding, mapping, dan applying. Hal tersebut sesuai dengan pendapat English yang menyatakan bahwa penalaran analogi merupakan model yang digunakan untuk memahami dan menarik kesimpulan baru pada situasi yang belum diketahui atau soal target (English, 2004). Siswa dengan kemampuan matematika tinggi melakukan identifikasi terhadap hubungan antara soal sumber dan soal target berdasarkan informasi yang diketahui maupun konsep matematika yang digunakan dalam penyelesaiannya. Selain itu siswa dengan kemampuan matematika tinggi juga mengetahui bagaimana cara menggunakan masalah sumber untuk memecahkan masalah target. Hal tersebut sejalan dengan pendapat Novick dan Holyoak yang menyatakan bahwa seorang siswa dikatakan melakukan penalaran analogi dalam memecahkan atau menyelesaikan masalah matematika jika siswa tersebut melakukan beberapa aktivitas seperti mengidentifikasi hubungan antara masalah target dengan pengetahuan yang telah dimiliki (sumber), melakukan identifikasi terhadap struktur masalah sumber yang sesuai dengan masalah target, mengetahui bagaimana cara menggunakan masalah sumber dalam memecahkan masalah target (Novick dan Holyoak, 1991). Mofidi dkk juga menyatakan bahwa penalaran analogi muncul ketika terdapat struktur khusus yang berkorespondensi antara objek-objek dan hubungan masalah sumber dan target digunakan untuk mengadaptasi solusi atau penyelesaian menggunakan prosedur analogi untuk memecahkan target (Mofidi dkk, 2012).

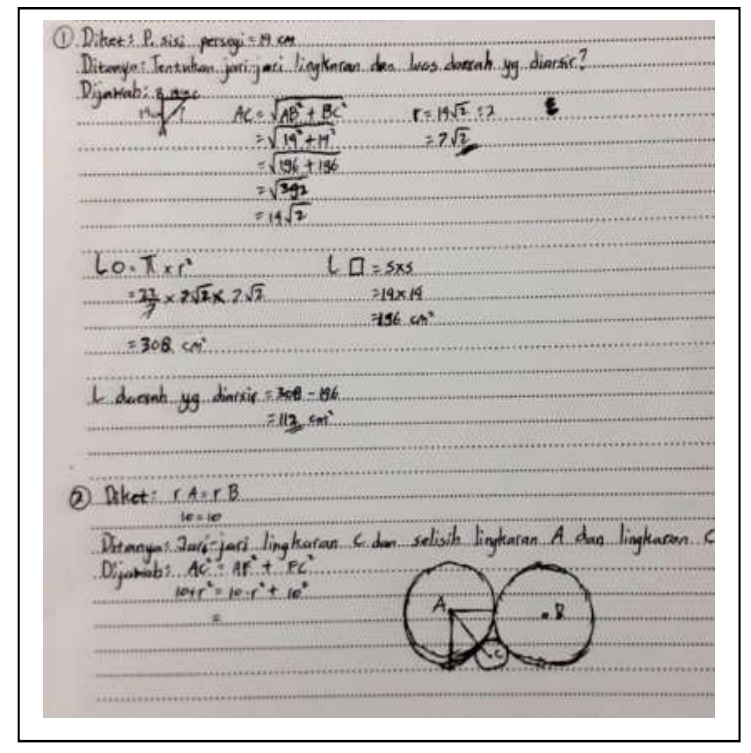

Gambar 1. Jawaban Subjek Berkemampuan Matematika Sedang

Berdasarkan gambar di atas siswa dengan kemampuan matematika sedang mengerjakan soal sumber dengan menyebutkan informasi yang diketahui dan konsep matematika yang digunakan dalam menyelesaikan soal sumber. Siswa tersebut juga menyelesaikan soal sumber berdasarkan konsep matematika yang sudah ia ketahui. Namun, ketika mengerjakan soal target, siswa dengan kemampuan matematika sedang hanya menyebutkan informasi yang diketahui dan apa yang ditanyakan pada soal target. Siswa berkemampuan matematika sedang kebingungan saat hendak menerapkan konsep matematika untuk menyelesaikan soal target. Siswa dengan kemampuan matematika sedang menghubungkan ketiga lingkaran pada soal target dan menerka konsep yang seharusnya digunakan untuk menyelesaikan soal target, namun sukar untuk menerapkannya. Proses penalaran analogi siswa dalam pemecahan masalah matematika 
meliputi encoding, inferring, encoding, dan mapping. Namun subjek hanya memenuhi satu dari dua indikator proses mapping yaitu menyebutkan konsep yang sama yang digunakan antara soal sumber dan soal target tanpa menjelaskan konsep yang digunakan pada soal target dan tidak bisa menyelesaikan soal target. Sehingga siswa dengan kemampuan matematika sedang hanya melakukan proses encoding, inferring, dan setengah proses mapping. Hal tersebut sejalan dengan pendapat Sa'dullah yang menyatakan kemampuan matematika memiliki keterkaitan dengan potensi seseorang meliputi pengetahuan dan keterampilan dalam berpikir, bernalar, memecahkan masalah, dan lain sebagainya (Sa'dullah, 2003).

Siswa dengan kemampuan matematika rendah menyelesaikan soal sumber seperti siswa dengan kemampuan tinggi dan sedang. Siswa dengan kemampuan matematika rendah menyebutkan informasi dan hal yang ditanyakan pada soal sumber dengan alasan yang logis. Siswa dengan kemampuan matematika rendah juga mengetahui konsep matematika yang digunakan untuk menyelesaikan soal sumber dan menerapkannya untuk menyelesaikan soal sumber. Subjek berkemampuan matematika rendah tak jauh berbeda dengan siswa berkempuan matematika sedang, siswa dengan kemampuan matematika rendah juga hanya menyebutkan informasi yang diketahui dan apa yang ditanyakan pada soal target. Berikut disajikan lembar jawaban siswa dalam menyelesaikan soal target.

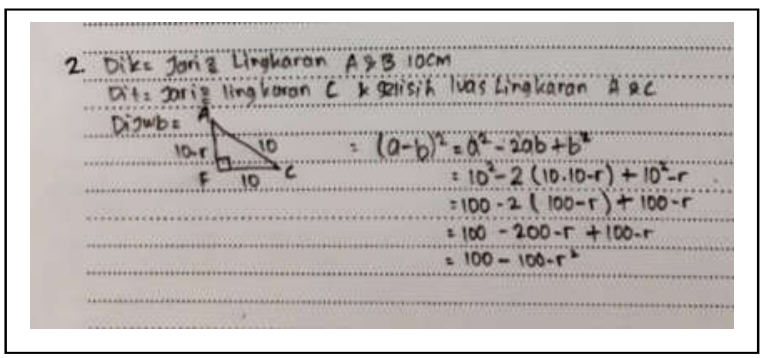

Gambar 2. Jawaban Subjek Berkemampuan Matematika Rendah terkait soal target

Ketika menyelesaikan soal target, siswa dengan kemampuan matematika rendah tidak ada gambaran sama sekali mengenai hubungan antara informasi maupun konsep matematika yang digunakan.

Tabel 1. Transkrip Wawancara Subjek Berkemampuan Matematika Rendah terkait Soal Target

\begin{tabular}{|l|l|}
\hline \multicolumn{2}{|c|}{ Transkrip Wawancara Subjek SR } \\
\hline P0012 & $\begin{array}{l}\text { Bagaimana dengan konsep yang digunakan } \\
\text { pada soal target? }\end{array}$ \\
\hline SS012 & $\begin{array}{l}\text { Sama dengan soal sumber kak, } \\
\text { menggunakan phytagoras juga tapi saya } \\
\text { tidak bisa menemukan segitiga siku-siku } \\
\text { yang digunakan untuk menentukan panjang } \\
\text { AC. }\end{array}$ \\
\hline P0013 & $\begin{array}{l}\text { Bisa tolong dijelaskan bagaimana cara } \\
\text { kamu menyelesaikan soal target? }\end{array}$ \\
\hline
\end{tabular}

\begin{tabular}{|l|l|}
\hline SS013 & $\begin{array}{l}\text { Dari titik A saya hubungkan ke tepi } \\
\text { lingkaran kak sehingga jadinya seperti ini } \\
\text { (menunjukkan gambar di lembar } \\
\text { jawabannya). Maka panjangnya titik A ke } \\
\text { tepi lingkaran } 10 \mathrm{~cm} \text {. Kemudian dari titik A } \\
\text { saya hubungkan ke bawah (menunjuk titik } \\
\text { yang dimaksud) panjangnya juga } 10 \mathrm{~cm} . \\
\text { Titik pusat A saya hubungkan dengan titik } \\
\text { pusat C. panjangnya sama dengan jari-jari } \\
\text { lingkaran A ditambah dengan jari-jari } \\
\text { lingkaran C. Jadi panjang AC itu 10 + r. } \\
\text { Seharusnya terbentuk segitiga tapi saya } \\
\text { tidak bisa menentukan panjangnya. Jadi } \\
\text { saya tidak dapat menyelesaikan soal target } \\
\text { karena kendala tersebut. }\end{array}$ \\
\hline
\end{tabular}

Sehingga siswa dengan kemampuan matematika rendah hanya melakukan proses penalaran analogi dalam pemecahan masalah matematika yaitu encoding dan inferring seperti siswa dengan kemampuan matematika sedang. Bedanya terletak pada siswa dengan kemampuan matematika sedang masih dapat menggambarkan hubungan dan menyebutkan konsep sama antara soal sumber dan soal target dan gambaran konsep yang akan digunakan untuk menyelesaikan soal target meski sukar untuk menjelaskannya, sementara siswa siswa dengan kemampuan matematika rendah sama sekali tidak menyebutkan pun menjelasakan konsep yang digunakan dalam menyelesaikan soal target. Sejalan dengan pendapat yang menyatakan bahwa hasil tes yang dirancang untuk mengukur kemampuan matematika telah menunjukkan bahwa siswa dengan kemampuan matematika rendah memperoleh nilai yang lebih rendah daripada siswa yang memiliki kemampuan matematika sedang hingga tinggi dalam penyelesaian konsep matematika (Galli, Chiesi \& Primi, 2008).

\section{PENUTUP}

\section{Simpulan}

Berdasarkan hasil penelitian dan pembahasan dapat ditarik kesimpulkan sebagai berikut.

1. Siswa dengan kemampuan matematika tinggi melakukan semua proses penalaran analogi dalam pemecahan masalah yaitu encoding, inferring, mapping, dan applying.

2. Siswa dengan kemampuan matematika sedang melakukan proses penalaran analogi meliputi encoding, inferring, encoding, dan mapping. Namun karena pada proses mapping hanya tercapai satu dari dua indikator maka proses mapping tidak terpenuhi dan siswa tersebut hanya melakukan dua proses penalaran analogi saja yaitu encoding dan inferring.

3. Siswa dengan kemampuan matematika rendah menyelesaikan soal sumber namun hanya menyebutkan informasi dan hubungan antara informasi pada soal sumber dan soal target sehingga siswa dengan kemampuan matematika rendah hanya 
melakukan proses penalaran analogi yaitu encoding dan inferring.

\section{Saran}

Berdasarkan hasil penelitian dan pembahasan yang telah dipaparkan di atas, berikut saran yang dapat dijadikan pertimbangan bagi peneliti lain jika akan melakukan penelitian serupa.

1. Dari hasil penelitian yang telah dilakukan diperoleh siswa dengan kemampuan matematika rendah dan sedang terhenti pada proses encoding dan inferring. Keduanya tidak dapat menjelaskan konsep yang digunakan dan tidak menyelesaikan soal target, sehingga indikator mapping dan applying tidak terpenuhi. Oleh sebab itu diharapkan peneliti lain yang akan melakukan penelitian serupa untuk memerhtikan perbedaan kemampuan matematika masing-masing subjek.

2. Agar tidak terjadi salah penafsiran terhadap soal sumber dan soal target, sebelum diberikan tes pemecahan masalah, peneliti memberi pengertian pada subjek mengenai pengertian soal sumber dan soal target.

3. Hasil penelitian menunjukkan bahwa siswa dengan kemampuan matematika rendah dan sedang terhenti pada proses encoding dan inferring. Keduanya tidak dapat menjelaskan konsep yang digunakan dan tidak menyelesaikan soal target, sehingga indikator mapping dan applying tidak terpenuhi dan proses tersebut tidak dilakukan, yang mana berkaitan dengan penghubungan antara soal sumber dan soal target. Dalam pembelajaran, hubungan tersebut sama halnya dengan contoh soal dan soal yang diberikan pada siswa. Oleh sebab itu diharapkan dalam pembelajaran, pengajar memberikan contoh lebih dari satu dan memastikan bahwa siswa dapat melalui proses mapping dan applying.

\section{DAFTAR PUSTAKA}

English, L. D. 1999. Reasoning By Analogy : A Fundamental Process in Children's Mathematical Learning. In Stiff LV Curcio PR (eds) Developing Mathematical Reasoning K-12 Reston. VA : NCTM, 22-36.

English, Lynn.D. 2004. Mathematical and Analogical Reasoning in Early Childhood. Mathematical and Analogical Reasoning of Young Learners.

Galli, S., Chiesi, F., \& Primi, C. (2008). The construction of a scale to measure mathematical ability in psychological students: An application of the Rasch model. Testing, Psychometrics, Methodology in Applied Psychology, 15(1), 3-18.

Gentner, D \& Loewen stein, J.2013.Learning: Analogical Reasonin Encoclopedia of Education, $2^{\text {nd }}$ Edition. New York: Macmilian

Menteri Pendidikan dan Kebudayaan Republik Indonesia. 2014. Peraturan Menteri Pendidikan dan Kebudayaan Republik Indonesia No. 58 tahun 2014 tentang Kurikulum $2013 \quad$ Sekolah Menengah Pertama/Madrasah Tsanawiyah. Jakarta.

Mofidi, A. Z. (2012). Instruction of Mathematical Concepts Through Analogical Reasoning Skills. Indian Journal of Science and Technology, vol.5

National Council of Teachers of Mathematics (NCTM).2000. Principles and standards for school mathematics. Reston, VA: NCTM.

Novick, L. R., dan Holyoak, K. J. 1991. Mathematical Problem Solving by Analogy. Journal of Experimental Psychology: Learning, Memory, and Cognition, V. 17, 398-415

Sa'dullah, Uyoh, 2003. Pengantar Filsafat Pendidikan. Alfabeta: Bandung

Vybihal, J. 1989. Search in Analogical Reasoning $11^{\text {th }}$ Annual Conference of Cognitive Society. New York : Michigan. 